\title{
Infecção natural pelo Vírus Sincicial Respiratório Bovino (BRSV) no Estado de Alagoas ${ }^{1}$
}

\author{
Paulo V. Peixoto ${ }^{2}$, Rinaldo A. Mota ${ }^{3}$, Marilene F. Brito ${ }^{4}$, Luís G. Corbellini ${ }^{5}$, David \\ Driemeier $^{6}$ e Maria Izabel de Souza ${ }^{7}$
}

\begin{abstract}
Peixoto P.V., Mota R.A., Brito M.F., Corbellini L.G., Driemeier D. \& Souza M.I. 2000. [Spontaneous BRSV infection in cattle of the state of Alagoas, Brazil.] Infecção natural pelo Vírus Sincicial Respiratório Bovino (BRSV) em bovinos no Estado de Alagoas. Pesquisa Veterinária Brasileira 20(4):171-175. Projeto Sanidade Animal Embrapa/UFRRJ, Km 47, Seropédica, RJ 23851-970, Brazil.

Cases of bovine respiratory syncytial virus (BRSV) infection affecting calves in the State of Alagoas, Brazil, are described. At least 220 calves, which were the progeny of Brown Swiss and Holstein Friesian cattle imported from Germany, Austria, and Uruguay, have died from the disease since 1995. Clinical signs included fever, dry cough, serous ocular discharge and, towards the final stages, marked dyspnea. On auscultation there were loud and harsh breathing sounds, and a strong wheezing could be heard from a distance. Histopathology of the lung revealed interstitial pneumonia associated with syncytial cells and infiltration by lymphocytes and eosinophils. A few plasma cells containing Russel bodies in their cytoplasm were also observed. There was hyperplasia of type II pneumocytes and mild squamous metaplasia of the respiratory epithelium. Bronchiolar epithelial cells and syncytial cells were positively stained with anti-BRSV antibody. The finding of BRSV infection in calves in Northeast Brazil plusidentical findings al ready reported from South Brazil, strongly indicate the need for a wide epidemiologic survey in order to evaluate the losses due to BRSV infection and the incidence of infected cattle. There is evidence that at least part of the imported animals involved in this outbreak was already infected on arrival at the port of Belém, in the State of Pará, Brazil.
\end{abstract}

INDEX TERMS: BRSV infection, cattle, Northeast Brazil.

RESUM O.- Descreve-se a ocorrência de infecção pelo vírus sincicial respiratório bovino (BRSV) em bezerros descendentes de animais das raças pardo-suíça e holandesa importados da Alemanha, Áustria, Suíça e Uruguai, na qual morreram em Alagoas, Brasil, pelo menos 220 cabeças, de 1995 até a pre-

\footnotetext{
${ }^{1}$ Aceito para publicação em 15 de agosto de 2000.

${ }^{2}$ Depto Nutrição e Pastagem, Instituto de Zootecnia, Universidade Federal Rural do Rio de Janeiro (UFRRJ), Km 47, Seropédica, RJ 23851-970.

3 Depto Medicina Veterinária, Universidade Federal Rural de Pernambuco (UFRPE), Rua Dom Manoel de Medeiros s/no, Dois Irmãos, Recife, PE 52171900.

${ }^{4}$ Depto Epidemiologia e Saúde Pública, Instituto de Veterinária, UFRRJ; email: marilene@ufrrj.br

${ }^{5}$ Mestrando em Ciências Veterinárias, Universidade Federal do Rio Grande do Sul (UFRGS), Cx. Postal 15094, Porto Alegre, RS 91540-000.

${ }^{6}$ Depto Patologia Clínica Veterinária, Fac. Vet., UFRGS, Cx. Postal 15094, Porto Alegre, RS 91540-000.

${ }^{7}$ Médica Veterinária, Clínica de Bovinos, Garanhuns, UFRPE.
}

sente data. 0 quadro clínico caracterizou-se por hipertermia, tosse seca, mais tarde dispnéia acentuada e por vezes lacrimejamento; à auscultação havia estertores secos, depois úmidos, com sibilos, muitas vezes audíveis à distância. 0 exame histológico revelou pneumonia intersticial com formação de células sinciciais, infiltração predominantemente linfocitária com presença de eosinófilos e de corpúsculos de Russel, proliferação de pneumócitos tipo II e leve metaplasia escamosa. Células epiteliais de bronquíolos e células sinciciais marcaram-se positivamente com o anticorpo anti-BRSV. A ocorrência da enfermidade no Sul e agora no Nordeste do Brasil indica a necessidade de se promover um amplo levantamento epidemiológico para se avaliar o grau de perdas e a proporção de animais infectados no país. Lembramos que parte dos animais importados, ao que tudo indica, já estavam infectados nos países de origem, quando desembarcaram em Belém, Pará.

TERMOS DE INDEXAÇÃO: Vírus Sincicial Respiratório Bovino, BRSV, bovinos, Nordeste do Brasil. 


\section{INTRODUÇÃO}

Através de observações sorológicas, clínicas e de cultivo viral tem-se verificado que o Vírus Sincicial Respiratório Bovino (BRSV), agente com a propriedade de induzir à formação de sincícios nos tecidos infectados ou cultivados, está muito difundido em todo mundo. A literatura o referencia como um importante patógeno primário no complexo Doença Respiratória Bovina (Baker 1993, Bryson 1993, van Vuuren 1994) e, ao que tudo indica, tem um significativo papel como agente desencadeante de infecções secundárias ou associadas (Kahrs 1985). Diversas referências a infecções associadas a vírus (BVD, parainfluenza-3 e adenovirus bovino) e a bactérias (Pasteurella sp, Streptococcus sp, Mycoplasma sp e Pseudomonas sp (Inaba et al. 1970, Lehmkuhl et al. 1979, Pirie 1981) demonstram a importância do BRSV como patógeno respiratório. Em bezerros, o BRSV foi identificado desde 1967; seu primeiro isolamento foi feito na Suécia por Paccaud \& Jacquier (1970). No Brasil, o primeiro registro da presença do vírus foi feita por Gonçalves et al. (1993), através de imunoflorescência e cultivo celular de amostras de tecido pulmonar de bezerros, coletadas em frigoríficos na Grande Porto Alegre, RS. Campalans \& Arns (1995) isolaram o BRSV, a partir da secreção nasotraqueal de bezerros com sintomas respiratórios, procedentes do Rio Grande do Sul. A primeira descrição da doença natural em bovinos de corte criados extensivamente foi feita no Rio Grande do Sul por Driemeier et al. 1997.

Este trabalho tem o intuito de registrar a ocorrência de surto de doença respiratória em bovinos causada pelo BRSV, em Alagoas, Brasil.

\section{MATERIAL E MÉTODOS}

0 histórico foi colhido pelo veterinário da fazenda. Nos locais de ocorrência dos surtos, em duas fazendas da bacia leitera de Alagoas, cerca de 20 bezerros foram examinados clinicamente e quatro daqueles muito enfermos foram sacrificados e necrospsiados.

Fragmentos de pulmão foram colhidos em formalina a $10 \%$ processados pelo método usual, cortados à espessura de $5 \mu \mathrm{m}$ e corados pela hematoxilina-eosina. 0 exame imunohistológico foi efetuado com anticorpo primário policlonal anti- BRSV ${ }^{8}$, (diluição de 1:700) em fragmentos de pulmão de dois bovinos, seguindo-se a técnica descrita por Mills (1992). Cortes histológicos de $5 \mu \mathrm{m}$ foram rotineiramente desparafinados em xilol, passados em álcool e água destilada. Em seguida bloqueou-se a peroxidase endógena com solução de peróxido de hidrogênio diluída em metanol por 30 minutos em temperatura ambiente. As lâminas histológicas foram submetidas a uma digestão prévia com tripsina a 0,1\%por 10 minutos a $37^{\circ} \mathrm{C}$ e posterior irradiação em forno microondas de uso doméstico por 2 minutos na potência máxima (1300 W). Durante esta etapa as lâminas ficavam imersas em $100 \mathrm{ml}$ de tampão citrato (pH 6,0). 0 bloqueio foi feito com soro fetal bovino (SFB) a $1 \%$ As amostras foram incubadas por 45 minutos a $37^{\circ} \mathrm{C}$ com anticorpo primário policlonal anti-BRSV a uma diluição de 1:700. A técnica de streptavidina-biotina foi empregada utilizando-se um kit comercial ${ }^{9}$, contendo anticorpo secundário biotinalado e streptavidina conjugada com peroxidase. Como cromógeno foi utilizada a diaminobenzidina (DAB). Os tecidos foram contra-corados com hematoxilina. No controle-negativo substituiu-se 0 anticorpo primário por SFB. As lavagens foram realizadas com solução de tampão fosfato PBS-pH 7,0).
"Swabs" pulmonares foram cultivados em ágar-sangue ovino a $10 \%$ em ambiente de anaerobiose, efetuando-se leituras às 24 e 48 horas.

\section{RESULTADOS}

\section{Dados epidemiológicos e clínicos}

Os surtos ocorreram em duas fazendas situadas no município de Viçosa, Alagoas. Na fazenda A havia 220 bovinos da raça pardo-suíça (dos quais 44 eram bezerros lactentes de até 30 dias), importados da Alemanha e da Áustria e na fazenda B, 600 bovinos das raças holandesa preto e branco e pardo-suíça, importados do Uruguai e da Suíça, respectivamente, dos quais 300 eram animais jovens.

$\mathrm{Na}$ fazenda $\mathrm{A}$, o sistema de criação era intensivo para exploração leiteira (leite tipo A). Os animais eram vermifuga$\operatorname{dos}^{10}$ e pré-munidos contra Babesia sp e Anaplasma sp. Utilizavam-se vacinas contra as seguintes doenças no rebanho: brucelose, leptospirose, IBR/BVD, manqueira, febre aftosa, mastite bovina (cepa Staphylococcus sp), parainfluenza-3 e Virus Sincicial Respiratório Bovino (introduzida no início de 1998, nos bezerros aos 4 meses de idade) porém o problema já havia se instalado e os efeitos da vacina contra BRSV não eram satisfatórios. Os animais eram avaliados a cada 6 meses para brucelose, leptospirose e tuberculose. Os primeiros animais foram importados da Alemanha e da Áustria em setembro de 1994. Na segunda importação, em dezembro de 1994, além do estresse da viagem, os animais sofreram privação alimentar no final do percurso. Quando os animais desembarcaram em Belém, Pará, alguns se apresentavam em condições precárias e al gumas vacas morreram logo após o desembarque, com doença respiratória diagnosticada como pasteurelose. Os animais desse mesmo lote seguiram para o Estado de Alagoas, e continuaram evidenciando o mesmo quadro clínico.

Nessa fazenda, as primeiras parições ocorreram em janeiro de 1995 e alguns bezerros apresentaram a doença respiratória logo nas primeiras semanas de vida. Após a ocorrência dos primeiros casos que culminaram em morte, mesmo com tratamentos convencionais e correções no manejo, os animais continuaram apresentando problemas respiratórios. Ao longo deste período morreram em torno de 50 bezerros. Os casos se sucederam, ano após ano, com intensificação da morbidade e da letalidade (principalmente no final de 1997), que se agravavam nos períodos de maior índice pluviométrico da região (maio a agosto); neste período observaram-se até cinco mortes por mês, coincidindo também com a maior taxa de parições (cerca de 50 a $70 \%$ contra apenas $10 \%$ no verão, em 1997). Em 1998, 30\%dos bezerros apresentaram quadro clínico de doença respiratória crônica. A morbidade e a letalidade eram mais elevadas nos animais jovens; foram raros os casos de morte em vacas, muito embora tenham sido observados alguns animais adultos magros e com tosse seca improdutiva, sem maiores complicações.

Já na primeira semana de vida os bezerros apresentavam

\footnotetext{
${ }^{8}$ VMRD, Pullman, USA.

${ }^{9}$ Dako LSAB + kit, Peroxidase, Carpinteria, USA.

${ }^{10}$ Ivermectina e levamisole.
} 

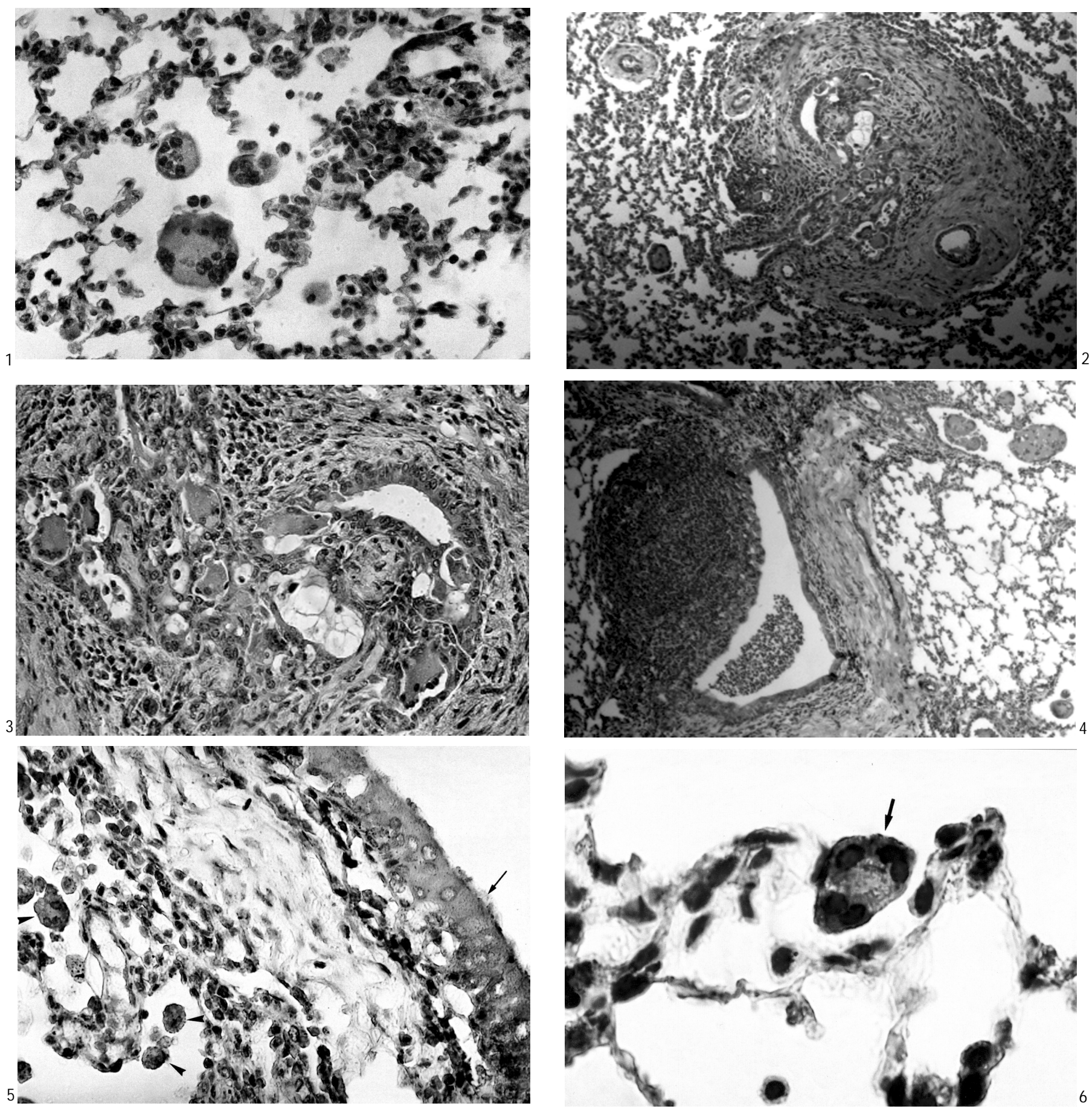

Fig. 1. Infecção natural pelo Vírus Sincicial Respiratório Bovino (BRSV). Presença de células sinciciais dentro de alvéolos. $\mathrm{HE}$, obj. 40.

Fig. 3. Detalhe da figura anterior. HE, obj. 25.

Fig. 5. Infecção natural pelo BRSV. Epitélio bronquial (seta) e células sinciciais e mononucleares (cabeça de seta) marcadas positivamente com anticorpo anti-BRSV. Obj. 25.

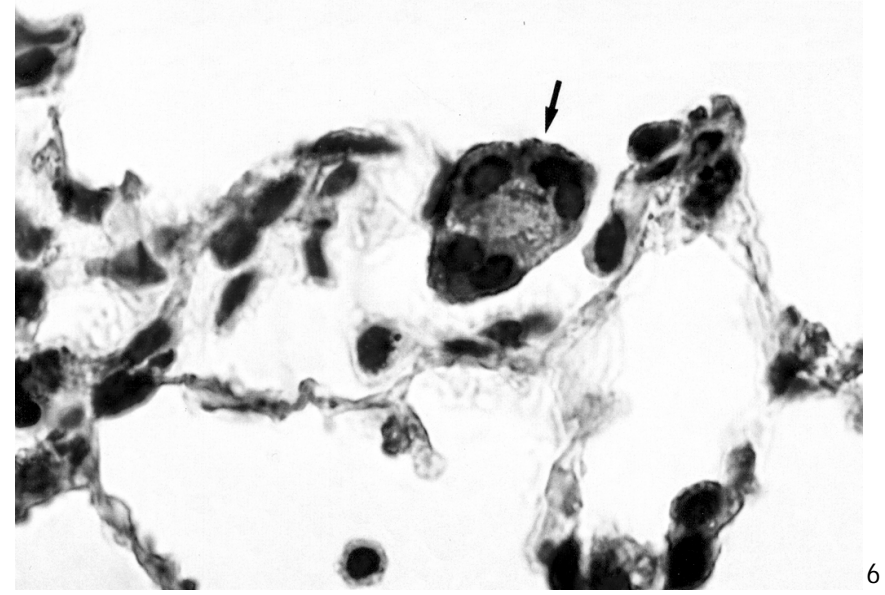

Fig. 2. Infecção natural pelo BRSV. Fibrose peribronquiolar. Distorção da estrutura bronquiolar, lembrando trombos recanalizados, bronquiolite obliterante. HE, obj. 10.

Fig. 4. Infecção natural pelo BRSV. Folículo linfóide peribronquiolar proeminente. HE, obj. 10.

Fig. 6. Infecção natural pelo BRSV. Célula sincicial no interior de alvéolo marcada positivamente com anticorpo anti-BRSV. Obj. 40. 
febre e tosse seca, geralmente sem produção de exsudato nasal. À percussão da área pulmonar notou-se aumento do limite caudal com presença de som subtimpânico nesta área. Foram ainda evidenciadas áreas de macicez na região cranioventral. À auscultação, inicialmente foram verificados estertores secos, depois úmidos com presença de sibilos, muitas vezes audíveis a certa distância. Na fase final da doença, os animais apresentavam dispnéia intensa, com extensão do pescoço e cabeça, cotovelos abduzidos, boca aberta e protrusão da língua. Alguns bezerros apresentavam corrimento nasal e ocular seroso e/ou purulento. Sialorréia e lacrimejamento foram observados menos freqüentemente. 0 quadro terminal culminava com apatia, graus variados de desidratação, dispnéia mista, taquicardia e ausência de febre. Com suporte terapêutico, os animais apresentavam quadro clínico evidente, mas não tão severo, resistiam até o desmame e tornavam-se progressivamente magros. Muitos bezerros, nessa fase e com estas condições clínicas, adquiriam infecção por Babesia bigemina e Anaplasma marginale. Após o tratamento, geralmente havia recidiva do problema respiratório, desta vez agravado, culminando com êxito letal.

Durante todos esses anos foram utilizados vários antimicrobianos (oxitetraciclina, penicilina, enrofloxacina, florfenicol, sulfas e tilosina, dentre outros), com recuperação clínica aparente apenas naqueles animais que apresentavam melhores condições orgânicas.

0 quadro clínico-epidemiológico vem sendo observado em rebanhos de propriedade vizinha, que cria intensivamente as raças holandesa preto e branco e pardo-suíça, importados do Uruguai e da Suíça, respectivamente (fazenda B). Nesta, apesar dos bezerros de ambas as raças permanecerem em bezerreiros coletivos, os da raça pardo-suíça eram acometidos com maior freqüência.

\section{Microbiologia pulmonar}

Dos "swabs" pulmonares observou-se crescimento de colônias branco-acinzentadas, não-hemolíticas, com $1 \mathrm{~mm}$ de diâmetro, que às 24 horas de incubação, pela coloração de Gram, revelaram características morfológicas de Staphylococcus Sp; às 48 horas de incubação houve aparecimento de colônias diminutas (0,5mm de diâmetro), acinzentadas e hemolíticas, ao Gram características de Corynebacterium bovis. Observou-se, ainda, crescimento de fungo filamentoso com hifas septadas.

\section{Alterações macroscópicas}

Os principais achados, à necropsia, restringiram-se ao sistema respiratório e em ambas as propriedades observaram-se as mesmas alterações. Os principais achados consistiram em conteúdo espumoso na traquéia; os lobos apicais, cardíacos e porções craniais dos lobos diafragmáticos apresentavam-se avermelhados, consolidados e ao corte exibiam exsudato purulento, típicos da pneumonia secundária. As demais porções apresentavam enfisema alveolar e intersticial difuso; ao corte observaram-se pequenas áreas irregulares e confluentes de cor branco-acinzentada. Os demais órgãos não apresentaram alterações macroscópicas.

\section{Achados histopatológicos}

Os cortes histológicos do pulmão evidenciam, principalmente dentro dos alvéolos do entorno de bronquíolos e brônquios, formação de numerosas células sinciciais misturadas à infiltração inflamatória mononuclear, com presença de numerosos polimorfonucleares eosinófilos, em algumas áreas. As células sinciciais (Fig. 1) apresentam-se como massas protoplasmáticas bem delimitadas, moderadamente eosinofílicas, por vezes granulares ou espumosas, contendo entre 3 e 40 núcleos normocromáticos, arredondados, ovóides ou reniformes, de tamanho variável, dispostos no centro ou perifericamente, contendo em geral apenas um nucléolo pouco proeminente. Por vezes, o mesmo tipo de exsudato e também as células sinciciais podem ser evidenciados dentro de bronquíolos terminais, em outros a infiltração inflamatória é tão marcada que há total consolidação do parênquima.

Observaram-se variáveis graus de fibrose peribronquial, peribronquiolar (Fig. 2) e também abaixo do epitélio dessas estruturas, que associada à inflamação, sobretudo linfocitária (com alguns corpúsculos de Russel), e a alterações proliferativas do epitélio, determina distorção e obstrução parcial ou total dessas vias aéreas, lembrando a estrutura de trombos recanalizados (bronquiolite obliterante) (Fig. 3); folículos peribronquiais e peribronquiolares são bastante proeminentes em algumas áreas (Fig. 4). Nos brônquios há focos de metaplasia escamosa, sem evidências de produção de queratina. Em alguns locais observa-se espessamento da parede de alvéolos seja por infiltração de eosinófilos, seja por focos de "epitelização" alveolar.

$\mathrm{Na}$ avaliação imunohistoquímica, células epiteliais de bronquíolos (Fig. 5), células sinciciais (Fig. 6) e algumas células livres na luz dos alvéolos (provavelmente células epiteliais - pneumócitos) marcaram-se positivamente com o anticorpo anti-BRSV nos dois casos testados.

\section{DISCUSSÃO E CONCLUSÕES}

0 aspecto histológico, com presença de células sinciciais no interior de alvéolos pulmonares, é característico para infecções pelo BRSV. As particularidades epidemiológicas e clínicas do surto aqui descrito também se encontram de acordo com o referido na literatura (Kahrs 1972, Pirie 1981, Van den Ingh 1982, Driemeier 1997, Dyer 1982). A replicação viral, demonstrada em células epiteliais na traquéia, brônquios, bronquíolos e células alveolares, confirma o BRSV como agente etiológico da enfermidade em questão. No presente estudo não foram encontradas evidências epidemiológicas ou histológicas da presença de agentes virais da IBR, da BVD e da parainfluenza, apenas focos supurativos determinados pela infecção bacteriana secundária.

A ocorrência de surto no Sul e agora no Nordeste do Brasil revela a extrema urgência de promover-se um levantamento clínico-epidemiológico abrangente com o intuito de avaliar o grau de perdas induzidas pelo agente no país. Lembramos que parte dos animais importados, ao que tudo indica já infectados nos países de origem, desembarcaram em Belém, PA. 


\section{REFERÊNCIAS}

Baker J.C. 1993. The characteristics of respiratory syncytial viruses. Food Animal Prentice. Vet. Med. 1190-1195.

Bryson D.G. 1993. Necropsy findings associated with BRSV pneumonia (Symposium on BRSV infection). Vet. Med. 894-899.

Bryson D.G., McNulty M.S., Logan E.F. \& Cush P.F. 1983. Respiratory syncytial viruspneumonia in young calves: clinical and pathologic findings. Am. J. Vet. Res. 44(9):1648-1655.

Campalans J.B. \& Arns C.W. 1995. Isolation of Bovine Respiratory Suncytial Virus in Brazil. Anais 5o Virológica 95, Ribeirão Preto, SP, B-34.

Driemeier D., Gomes M.I.P., Moojen V., Arns C.W., Voog G., Kessler L. \& Costa U.M. 1997. Manifestação clínico-patológica de infecção pelo Vírus Respiratório Sincial Bovino (BRSV) em bovinos de criação extensiva no Rio Grande do Sul, Brasil. Pesq. Vet. Bras. 17(2):77-81.

Dyer R.M. 1982. The bovine respiratory disease complex: a complex interaction of host, enviromental and infectious factors. Comp. Collect. 4(7):52-61

Gonçalves I.P.D., Simanke A.T., Jost H.C., Hötzel I., Dal Soglio A. \& Moojen V. 1993. Detection of bovine respiratory syncytial virus in calves of Rio Grande do Sul, Brazil. Ciência Rural, Santa Maria, 23(3):389-390.
Inaba Y., Tonaka I., Omori T. \& Matumoto M. 1970. Isolation of bovine respiratory syncytial virus. Japan J. Exp. Med. 40:473-474.

Kahrs R.F. 1985. Enfermidades víricas del Ganado Vacuno. Acribia, Zaragoza, p. 267-274.

Lehmkuhl H.D. \& Cutlip R.C. 1979. Experimental respiratory syncytial virus infection in feder-age of lambs. Am. J. Vet. Res. 40(12):1729-1730.

Mills B. 1992. Immunohistochemistry, p. 247-255. In: Prophet E.B., Mills B., Arrington J.B. \& Sobin L.H. (ed.) Laboratory Methods in Histotechnology. AFIP, Washington.

Paccaud M.F. \& Jacquier C. 1970. A respiratory syncytial virus of bovine origin. Arch. Gesamte Virusforschung 30:327-342.

Pirie H.M., Petrie L., Pringle C.R., Allan E.M. \& Kennedy G.J. 1981. Acute fatal pneumonia in calves due to respiratory syncytial virus. Vet. Rec. 108:411416.

Stewart R.S. \& Gershwin L.J. 1989. Role of IgE in the pathogenesis of bovine respiratory synsytial virus in sequential infections in vaccinated and nonvaccinated calves. Am. J. Vet. Res. 50(3):349-355.

Van Den Ingh T.S.G.A.M., Verhoeff J. \& Van Nieuwstadt A.P.K.M.I. 1982. Clinical and pathological observations on spontaneous bovine respiratory syncytial virus infections in calves. Res. Vet. Sci. 33:152-158.

Van Vuuren M. 1994. Bovine respiratory syncytial virus infection, p. 769-772. In: Coetz J.A.W., Thomson G.R. \& Tustin R.C. (ed.) Intifectious Diseases of Livestock. Oxford University Press, Cape Town. 